\title{
Factors Predicting Success of Laparoscopic Adrenalectomy: Our Experience
}

\author{
Varun Agarwal ${ }^{1}$, Amit Sharma $^{2}$, Mukund Andankar ${ }^{3}$, Hemant Pathak ${ }^{4}$
}

\begin{abstract}
Introduction: Adrenal is one of the most feared organs owing to its anatomical position. However, adrenalectomy by laparoscopic means has now been adopted as the procedure of choice to treat benign and malignant functioning and nonfunctioning adrenal tumors. We describe our experience with laparoscopic adrenalectomy (LA) in 37 patients at a tertiary institute and try to predict factors for open conversion.

Materials and methods: Thirty-seven patients who underwent LA from August 2013 to February 2018 were retrospectively analyzed and factors leading to conversion to open adrenalectomy assessed.

Results: Among 37 patients, 31 had pheochromocytoma on histopathology and 1 patient had adrenal hyperplasia leading to Cushing's syndrome. Five out of 37 patients had to be converted to open technique-multiple adhesions with the bowel, retrocaval tumor extensions, difficult dissection, and prolonged operative time due to large tumor size (in two patients) and severe hepatomegaly were the reasons for conversion to open.

Conclusion: Laparoscopic adrenalectomy is safe and feasible for large adrenal lesions.

Keywords: Adrenalectomy, Laparoscopic, Success.

World Journal of Laparoscopic Surgery (2020): 10.5005/jp-journals-10033-1422
\end{abstract}

\section{INTRODUCTION}

Adrenalectomy is often performed by surgeons with an interest or training in endocrine surgery. Adrenal is one of the most feared organs because of its deep retroperitoneal location and close relation to vital structures. Adrenalectomy by laparoscopic means is one of the successful applications of minimally invasive surgical techniques. It has now been adopted as the procedure of choice to treat benign and malignant functioning and nonfunctioning adrenal tumors. ${ }^{1}$ Adrenalectomy was initially done by open surgery when Sargent performed the first planned adrenalectomy in $1914 .{ }^{2}$ However, laparoscopic adrenalectomy (LA) is now being done also for hypervascular tumors and large benign and malignant adrenal tumors. ${ }^{3}$

We report our experience in 37 patients who underwent LA and the factors which affected their conversion to open in 5 cases.

\section{Materials and Methods}

Thirty-seven patients who underwent LA from August 2013 to February 2018 were retrospectively analyzed based on age, sex, and detailed history which would suggest a syndromic association or past history of abdominal surgery. The weight and height of patients were taken to calculate the body mass index (BMI).

The department of endocrinology at our institute primarily evaluated these patients. Depending on the suspected pathology, an appropriate hormonal workup was done and patients with functional as well as nonfunctional tumors were referred to us for surgical management. The ones with functional tumors like pheochromocytoma and Cushing's syndrome were stabilized preoperatively.

All patients underwent contrast-enhanced computerized tomography (CECT) and/or magnetic resonance imaging (MRI) for delineating the size of the gland, relation with inferior vena

\begin{abstract}
1,3,4 Department of Urology, Topiwala National Medical College and BYL Nair Hospital, Mumbai, Maharashtra, India

${ }^{2}$ Department of Urology, All India Institute of Medical Sciences, Raipur, Chhattisgarh, India
\end{abstract}

Corresponding Author: Amit Sharma, Department of Urology, All India Institute of Medical Sciences, Raipur, Chhattisgarh, India, Phone: +91 8691898668, e-mail: dramiturology@gmail.com

How to cite this article: Agarwal V, Sharma A, Andankar M, et al. Factors Predicting Success of Laparoscopic Adrenalectomy: Our Experience. World J Lap Surg 2020;13(3):125-127.

Source of support: Nil

Conflict of interest: None

cava (IVC) on the right side, the renal vein on the left side, and the presence or absence of lymph nodes.

The success of laparoscopic surgery was defined as completion of the entire surgery by laparoscopic means. If, at any point during the surgery, there occurred a difficulty or a complication that was not manageable laparoscopically, the patient was converted to open surgery.

Patients with suspicion of malignancy, tumor invasion of adjacent organs, and patients who were high risk due to cardiopulmonary disease were excluded from the study.

All specimens, after extraction, were sent for a histopathology examination.

\section{Technique}

All patients were operated on under general anesthesia and a lateral transabdominal flank approach was used with an intraabdominal pressure of $12 \mathrm{~mm} \mathrm{Hg}$. Wherever necessary hemostasis was achieved using bipolar coagulation, Harmonic scalpel, Ligaclips, Hem-o-lok clips.

(-) The Author(s). 2020 Open Access This article is distributed under the terms of the Creative Commons Attribution 4.0 International License (https://creativecommons. org/licenses/by-nc/4.0/), which permits unrestricted use, distribution, and non-commercial reproduction in any medium, provided you give appropriate credit to the original author(s) and the source, provide a link to the Creative Commons license, and indicate if changes were made. The Creative Commons Public Domain Dedication waiver (http://creativecommons.org/publicdomain/zero/1.0/) applies to the data made available in this article, unless otherwise stated. 


\section{Right Adrenalectomy}

(Fig. 1) Four ports were used normally. Three ports of $10 \mathrm{~mm}$ (1 for 30 degree scope and 2 as working ports) each were placed along the right costal margin and one $5 \mathrm{~mm}$ port at the xiphisternum for liver retraction. An additional $5 \mathrm{~mm}$ fifth port would be inserted for liver retraction if required, in the right anterior axillary line.

The triangular ligament was first cut and the peritoneum was incised along with the liver as far as the diaphragm so that the right lobe of the liver falls away medially. The plane was created between liver and adrenal and dissection proceeded medially reaching the adrenal vein.

After complete dissection of the vein, it was cut between clips. The gland was then dissected free using a hook with monopolar coagulating current and delivered after placement in endobag. The specimen was extracted via a $10 \mathrm{~mm}$ port, by enlarging the incision. The port sites were closed using the standard technique.

\section{Left Adrenalectomy}

Port placement on the left side was similar to the right. Four ports were used.

The peritoneum was incised along the White Line of Toldt in a "T" shaped manner.

The two horizontal limbs of T extended from colon caudally to splenocolic ligament in the cephalad direction till the greater curvature of the stomach was visible.

This allowed complete retraction of the spleen and the colon by positional gravity and exposed the kidney enveloped in the Gerota's fascia. The vertical limb of " $T$ " was the line of dissection between the tumor and spleen. Dissection was done at the site of the renal hilum, for identification of the adrenal vein, which was clipped and divided. The adrenal gland was then dissected free from the surrounding structures and delivered in a retrieval bag.

\section{Results}

The demographic details and patient characteristics have been summed up in Table 1. Out of 37 patients, 32 were evaluated and found to have functional tumors. Eventually, 31 of them had pheochromocytoma on histopathology and 1 patient had adrenal hyperplasia leading to Cushing's syndrome. One patient had sudden cardiovascular collapse at the time of induction but was resuscitated on time and the patient went on with the surgery successfully. Most

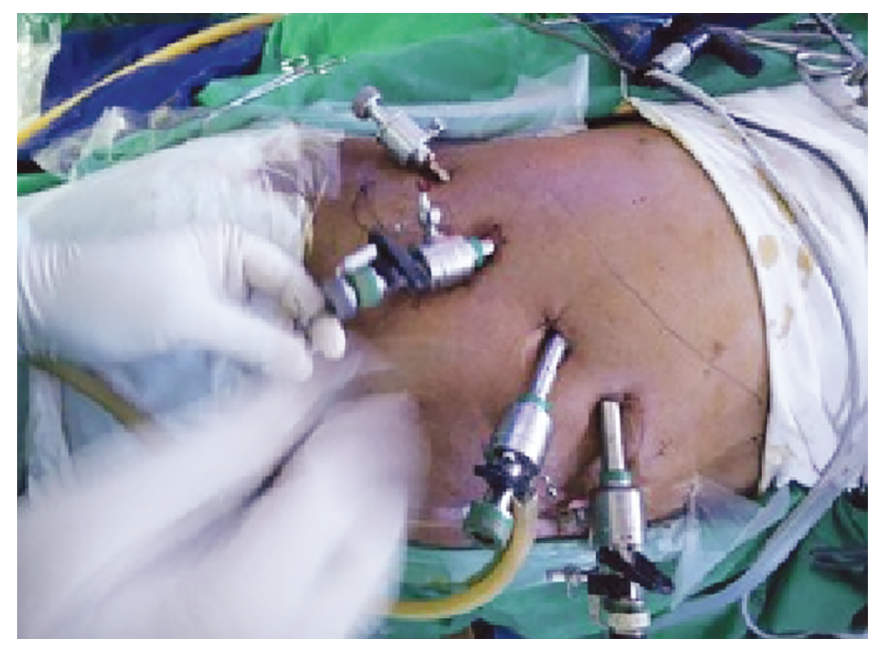

Fig. 1: Port placement for right adrenalectomy of the patients had intraoperative fluctuations of blood pressure which was managed successfully by an anesthetist. These patients eventually had pheochromocytomas on histology. The patient who was pregnant had intraoperative accelerated hypertension with a maximum recording of $230 / 110 \mathrm{~mm} \mathrm{Hg}$, managed by inj. nitroprusside and nitroglycerine (NTG) drip.

Five out of 37 patients had to be converted to the open technique. One of them had multiple adhesions with the bowel because of past abdominal surgery for duodenal perforation which made the separation of bowel difficult. One patient had retrocaval tumor extensions and was densely adherent to IVC and liver with a size of $8.5 \times 7 \mathrm{~cm}$. It eventually turned out to be adrenocortical carcinoma. Two patients were converted to open because of the difficulty in dissection and prolonged operative time due to large tumor size. One of the patients had severe hepatomegaly. Despite adding a fifth retraction port, separation of tumor from the liver bed was difficult, so the decision was taken to proceed with open surgery. The characteristics of patients converted to open along with reasons for the same have been summed up in Table 2.

\section{Discussion}

Studies have suggested that large tumors are not a contraindication for LA, but some authors do not approve laparoscopic approach for large tumors because of increased risk of malignancy, especially in tumors with infiltration to surrounding structures on computerized tomography (CT), which may even lead to peritoneal dissemination

Table 1: Patients' characteristics

\begin{tabular}{ll}
\hline Total patients & 37 \\
Mean age in years (range) & $46(27-65)$ \\
Sex & Male-15 (40.54\%) \\
& Females-22 (59.45\%) \\
Average BMI in kg/m² (range) & \\
Side & Right-16 (43.24\%) \\
& Left-20 (54.05\%) \\
& B/L-1 (2.7\%) \\
Any significant history & 1 female-5 months pregnant \\
& 1 male-past history of abdominal \\
Mean size in cm (range) & surgery for duodenal perforation \\
Functional tumors & 6.05 cm (2.5-9.6 cm) \\
Final histopathology & 32 (31 pheochromocytomas and 1 \\
& patient of Cushing's disease) \\
& $\begin{array}{l}\text { Nonfunctioning adenomas-4 } \\
\text { Pheochromocytoma-31 }\end{array}$ \\
& Adrenocortical carcinoma-1 \\
& Adrenal hyperplasia-1 \\
\hline
\end{tabular}

Table 2: Reasons for conversion to open adrenalectomy

\begin{tabular}{ll}
\hline No. of patients converted to open & Reason for conversion \\
\hline 1 & $\begin{array}{l}\text { Hepatomegaly in a right-sided } \\
\text { tumor }\end{array}$ \\
1 & $\begin{array}{l}\text { Adherent to kidney, liver, and } \\
\text { retrocaval extension-eventu- } \\
\text { ally malignant }\end{array}$ \\
& Large tumor size \\
1 & Past abdominal surgery leads to \\
& adhesions with bowel \\
\hline
\end{tabular}


or port site recurrence. ${ }^{4-7}$ In the present study, the laparoscopic approach was adopted in all patients with adrenal tumors regardless of tumor size. Two patients were converted to open adrenalectomy because of large tumor size.

However, the size of the tumor can be regarded as the most important factor for conversion. ${ }^{8}$

In recent literature, contraindications for LA are invasive adrenocortical carcinoma, large tumor $>10-12 \mathrm{~cm}$ in diameter, and malignant adrenocorticotropic hormone (ACTH) secreting pheochromocytoma with lymphadenopathy and adrenocortical carcinoma with caval thrombus. ${ }^{9}$ Patients with malignancy or suspicion of malignancy were not included in the study.

One patient in our study underwent bilateral LA for adrenal hyperplasia because of ectopic ACTH secreting adenoma in the lung. Here, the laparoscopic approach is much preferred when compared with the open approach, as bilateral laparoscopic adrenal surgery leads to much less tissue injury in immunocompromised patients with a risk of delayed wound healing. It also enables better visibility of the surgical field because of an additional advantage of magnification, thus decreasing the risk for retained remnants and adrenal rest tissue. ${ }^{10}$

Right adrenal gland-more retrocaval and a shorter adrenal vein than left adrenal gland, so right side is a more challenging and time-consuming procedure than left-sided adrenalectomy. ${ }^{11}$ However, Po-Hui Chiang et al. did not find any difference in conversion rates based on the laterality of tumors. ${ }^{12}$

Prior abdominal surgery ${ }^{13}$ leads to prolonged operating times, increased technical difficulty, increased risk in initial entry into the abdominal cavity, and increased chances of causing injury to the surrounding organs. Morris et al. showed a trend for longer operative times in patients with previous surgery; however, the difference was not significant. ${ }^{14}$

Pheochromocytomas, being larger and more vascular when compared with other adrenal neoplasms, are a challenge to resect and lead to more complications, longer operative times, and more conversions to open procedure. ${ }^{15}$

Zografos et al., in their study, have linked obesity with a higher incidence of conversions because of difficult cannula placement, excessive intraperitoneal fat obscuring the anatomy, excessively thick abdominal wall causing difficulties in the manipulation of instruments, thereby leading to longer operating times. ${ }^{16}$

\section{Conclusion}

Laparoscopic adrenalectomy can be adopted even for large adrenal lesions and is safe and feasible. The laparoscopic attempt should be given even for large and malignant adrenal tumors; however, conversion to open surgery should not be delayed to avoid an adverse outcome.

There is an increased risk of conversion to open surgery in patients with:

- Large tumors ( $\geq 5 \mathrm{~cm})$, (size-most important).

- Malignancy.
- Right-sided tumors.

- History of past abdominal surgery.

This information can help in appropriate counseling and taking of preoperative consent of candidates for $L A$.

Laparoscopic adrenalectomy can also be carried out safely in a pregnant woman without harm to the fetus.

\section{References}

1. Gagner M, Lacroix A, Bolte E. Laparoscopic adrenalectomy in Cushing's syndrome and pheochromocytoma. N Eng J Med 1992;327(14):1033. DOI: 10.1056/NEJM199210013271417.

2. Chow GK, Blute ML. Surgery of the adrenal glands. In: Wein AJ, Kavoussi LR, Novick AC, Partin AW, Peters CA, ed. Campbell-Walsh Urology. 9th ed., Philadelphia: WB Saunder; 2007. pp. 1868-1888.

3. Tsuru N, Suzuki K. Laparoscopic adrenalectomy. J Min Access Surg 2005;1(4):165-172.

4. Henry JF, Defechereux T, Gramatica L, et al. Should laparoscopic approach be proposed for large and/or potentially malignant adrenal tumors? Langenbecks Arch Surg 1999;384(4):366-369. DOI: 10.1007/ s004230050215.

5. Hobart MG, Gill IS, Schweizer D, et al. Laparoscopic adrenalectomy for large-volume ( $>$ or $=5 \mathrm{~cm}$ ) adrenal masses. J Endourol 2000;14(2):149154. DOI: 10.1089/end.2000.14.149.

6. MacGillivray DC, Whalen GF, Malchoff CD, et al. Laparoscopic resection of large adrenal tumors. Ann Surg Oncol 2002;9(5):480-485. DOI: $10.1007 /$ BF02557272.

7. Henry JF, Sebag F, lacobone M, et al. Results of laparoscopic adrenalectomy for large and potentially malignant tumors. World J Surg 2002;26(8):1043-1047. DOI: 10.1007/s00268-002-6666-0.

8. Shen ZJ, Chen SW, Wang S, et al. Predictive factors for conversion of laparoscopic adrenalectomy: a 13 year review of 456 cases. J Endourol 2007;21(11):1333-1337. DOI: 10.1089/end.2006.450.

9. Young Jr WF, Thompson GB. Laparoscopic adrenalectomy for patients who have Cushing's syndrome. Endocrinol Metab Clin North Am 2005;34(2):489-499. DOI: 10.1016/j.ecl.2005.01.006.

10. Young Jr WF, Thompson GB. Role for laparoscopic adrenalectomy in patients with Cushing's syndrome. Arq Bras Endocrinol Metab 2007;51(8):1349-1354. DOI: 10.1590/S0004-27302007000800021.

11. Rieder JM, Nisbet AA, Wuerstle MC, et al. Differences in left and right laparoscopic adrenalectomy. JSLS 2010;14(3):369e73. DOI: 10.4293/1 $08680810 \times 12924466007520$.

12. Chiang $\mathrm{PH}, \mathrm{Yu} \mathrm{CJ}$, Lee WC, et al. Is right-sided laparoscopic adrenalectomy truly more challenging than left-sided? the 10 year experience of a single institute. Urol Sci 2013;24:117-119. DOI: 10.1016/j.urols.2013.07.001.

13. Curet M. Special problems in laparoscopic surgery: previous abdominal surgery, obesity, and pregnancy. Surg Clin North Am 2000;80(4):1093-1110. DOI: 10.1016/S0039-6109(05)70215-2.

14. Morris L, Ituarte $P$, Zarnegar R, et al. Laparoscopic adrenalectomy after prior abdominal surgery. World J Surg 2008;32(5):897-903. DOI: 10.1007/s00268-007-9438-z.

15. Chan J, Meneghetti AT, Meloche RM, et al. Prospective comparison of early and late experience with laparoscopic adrenalectomy. Am J Surg 2006;191(5):682-686. DOI: 10.1016/j.amjsurg.2006.01.042.

16. Zografos GN, Markou A, Ageli C, et al. Laparoscopic surgery for adrenal tumors: a retrospective analysis. Hormones (Athens) 2006;5(1):52-56. DOI: 10.14310/horm.2002.11168. 